\title{
A North American Indigenous Narrative-based Inquiry of Culture and Land
}

\author{
Dr. Jonathan Pitt (Corresponding author) \\ Indigenous Studies/Education, Nipissing University \\ 100 College Drive, North Bay, ON P1B 8L7, Canada \\ E-mail: jonathap@nipissingu.ca
}

Received: November 9, 2021 Accepted: January 15, 2022 Published: January 16, 2022

doi:10.5296/ijch.v9i1.19451 URL: https://doi.org /10.5296/ijch.v9i1.19451

\begin{abstract}
This research uses a narrative cultural inquiry study to address the need to save the land our Mother Earth (Aki) and the relationship with Indigenous Spirituality through the topics/themes of Spirit Houses, Sa'be (Sasquatch) and Sacred landscape features such as Spiritual Sites, Ceremony and Pictographs within the geography of Turtle Island, North America in Northern Ontario, Canada. The rationale of this study was to address the larger inaadiziwin (philosophy) of Indigenous character and way of life with nature or "All My Relations" for the author.
\end{abstract}

Keywords: culture, history, indigenous, first nations, mother Earth, environment, Sasquatch, indigenous spirituality, spirit houses, spiritual sites, ceremony and pictographs

\section{Introduction}

In this personal narrative I contend that our Mother Earth (Aki/Ahki) is in peril, some may find that too strong a statement, however, the tell-tale signs have been in our faces for far too long. The way in which we view Mother Earth in mainstream society is that of a natural resource to be cut down, mined, consumed, used entirely in a one-way relationship. Canada as a colonial enterprise has been predicated on the notion that Turtle Island is a bounty to be depleted as it began in the fur trade and early fisheries. Reconciliation for Indigenous people and the planet is desperately needed. The recent global events of COVID-19 have shifted our attention away from important concerns for both Indigenous Peoples and Mother Earth. Prior to the established pandemic, the wild fires of Australia occurred and within Canada, railroad blockades protesting injustices towards protesters in British Columbia were daily news headlines. When combined with the growing unrest towards governmental ineptitude worldwide, the epidemic shifted humanity's focus off the bull's eye. Discrimination of 
Indigenous protesters and environmental exploitation was a daily pastime for mainstream culture in the early months of 2020.

Early fisheries of abundance off the east and west coast of Canada (as Canadian's used to say the water ran black with cod fish) are an accurate historical microcosm of what has occurred to the land and water of Turtle Island on a larger scale and the crown's strategic and profitable relationship with Indigenous peoples via a terra nullius-mindset and duplicitous treaties all the while relying on fragile theories such as the Bering land bridge to inculcate the doctrine of discovery in mainstream schooling on the population. Indigenous health and well-being, stolen Indigenous identity, via residential schools and chronological and contemporary colonialism, have all been continuing contributing factors to systemic racism, a lost relationship with culture and the land (Switzer, 2017).

Throughout this personal narrative I will address inaadiziwin (philosophy) of Indigenous character and way of life with nature or "All My Relations" as I discuss the relationship between the land our Mother, Aki and Indigenous Spirituality through the topics/themes of Spirit Houses, Sa'be (Sasquatch) and Sacred landscape features such as Spiritual Sites, Ceremony and Pictographs.

\section{Spirit Houses}

Boozhoo (hello) as I make my way around the medicine circle of my life, I have now passed the halfway point. The question I often ask myself is: Have I made a difference? If I can answer honestly 'yes' then I am happy, if I cannot then I have work ahead of myself as I move closer to the happy hunting grounds to be with my Ancestors. My wish is to be cremated, no expensive Western Eurocentric visitation or funeral, only my ashes laid to rest in the river where I have been hunting since I was a small boy, it is the place I am most at peace, connected to the land, to my Ancestors. I have heard of Indigenous practices with Spirit Houses and seen them, although they are not Pan-Indigenous-ism or a Pan-Indian practice. In an article in the fall of 2019, I was quoted as stating:

The Spiritual practices of Indigenous groups within Turtle Island are not homogenous and vary greatly as do the differences in customs, rituals and traditions between and amongst each group, for example, the differences between Haudenosaunee and Anishinaabeg but also differences within each group of First Peoples when recognizing specific First Nation to First Nation variances. Prior to European contact and the influence of Christianity, Indigenous communities functioned as independent republics and often were matriarchal. The practice of spirit houses is not universal, my personal experiences participating in First Nations death rituals within my family often involves staying with the body of the deceased at all times and keeping a sacred fire for four days and nights leading up to the funeral. The mourning of the dead and preparing for the transition to the Spirit World takes place during this time. (Pitt, J., as quoted in Steer, B., November 2019)

Our Indigenous death practices and rituals have long been misunderstood and still in contemporary society we see systemic racism and a lack of compassion with Eurocentric capitalist-style bereavement leave policies when insufficient time is allocated for Indigenous rituals or when Human Resource departments tell employees "if the funeral is on Thursday you can be off work on Thursday" and so on. It is the classic colonizer and colonized narrative at 
work in mainstream society today. Similarly, settler society and Christianity have worked in tandem to impose the Eurocentric allocations of grieving on Indigenous ways:

My sense is contact with European Christianity involving missionaries, settlers and government control (i.e. The Indian Act) has had a direct impact or created a dualism of Spirituality and Christianity fused practices we often see with Indigenous death rituals in contemporary times both on and off-reserve. The blending of beliefs of Indigenous and Western Eurocentric Worldviews in my mind has contributed to the conditions for 'spirit houses' or 'gravehouses' as we currently know them. Historically some Indigenous groups would cover graves with stones to protect and provide shelter for the Spirit and body of the deceased similar to spirit houses. The length of time the Spirit needs to transition to the Spirit World also varies amongst Indigenous Peoples and by geographic location. This may be a contributing factor to the usage of spirit houses as in some cultures the dead take longer to travel across the physical to Spirit World. It allows the living a place to visit and some cultures provide (or leave) objects with the deceased. (Pitt, J., as quoted in Steer, B., November 2019)

I know than in some far North communities, Indigenous cultures require approximately 40 days for this journey. We must also remember that Native kinship with environment has been and continues to be the great determiner. Cremation was once more widely practiced until Christianity interment outlawed other practices as being associated with Heathenism. Christian funeral rites, such as earth burial have contrasted globally with Indigenous cremation practices which Indigenous ancestors understood that cremation could also prevent the spread of epidemics.

Constructs such as Traditional Ecological Knowledge (TEK) and the Honourable Harvest as noted by Indigenous Scholars such as Robin Wall Kimmerer (Kimmerer, 2013, p. 151) and beliefs such as 'All my Relations' would not have incorporated harvesting trees for spirit houses in some cultures as the dwellings used in the Woodlands regions did not typically use lumber or box style housing currently employed today. When we think of these fundamental Indigenous belief concepts such as 'All My Relations' Indigenous people living the practice of the Honourable Harvest and a life (plant or animal) for a life (human) and cutting down trees for cemetery houses has not been a universal practice. Indigenous cultures typically view humans as the younger brothers of creation after plants (Kimmerer, 2013, p. 9). Within an Indigenous group such as the Anishinaabeg on Mnidoo Mnising (Manitoulin Island), practices would vary, for instance, the well-known burial cave of Huron or Ojibway on Manitoulin Island highlights how varied rituals are within an island and could be unlike the Christianity ceremonial religious method of 'one way' of doing things.

\section{Sabe (Sa'be) Also Known as Sasquatch}

Making a difference and following the right path in life in my mind means to follow the Seven Grandfather Teachings, the toughest one for me has always been honesty. Not honest in a liar, in a liar way or meaning, but with those half truths or withholding information to protect the feelings of others. In the Seven Grandfather Teachings, it is Sabe (Sa'be) who represents them. The First Nations of Turtle island or North America may have been around for tens of thousands of years by some experts (Pre-Clovis) and radiocarbon evidence dated to 
over 9,500 years or 11,000 years ago (time in our years) and it is undisputed fact of the existing Paleo-Indian culture that existed right here in Northern Ontario (i.e. the Sheguiandah site on Manitoulin Island).

Some pre-first contact pictographs in North America are thought to represent the Sabe (Sa'be), Sasquatch or Bigfoot, however, we must remember the artist's representation of Spiritual visions \& dreams through ochre. There are generally understood elements of Sasquatch:

The oral history in some communities would indicate that the Sabe is viewed as a protector or guardian of Mother Earth \& thought of as a peaceful creature when left alone by some first peoples. Not the werewolf-beast like creature of contemporary lore \& Hollywood movies. One Native Elder once said that there are areas where the Sabe live and we do not go there, we live here and they live there $\&$ that he used to walk among us. The song "let it be" by the Beatles always comes to mind. It is a common understanding amongst Native peoples that if we don't bother Sabe in his habitat he won't bother us in suburbia; best left that way in my mind if researchers think they could grow to over seven and a half feet. (Pitt, J., as quoted in Steer, B., April 2018)

Something to keep in mind as the human population spirals and urban blight \& sprawl continues; perhaps we are encroaching on more than just wetlands when we build the next golf course? There is Indigenous oral history to suggest that many years prior to European contact, First Nations lived in harmony with the animals and could speak to the animals and communicate as we do. However, it is also a common understanding that we have lost much of our knowledge on this and more. Native Medicine societies, such as Midewin/Mediwiwin (various spellings) and others know in English as Shaman, Medicine Men, Shaking Tent and more have been persecuted both North \& South of the border. For example, Native dances such as the Sundance and jingle dress, the latter jingle dress for healing, when not understood have been considered witchcraft by some. Remember, you cannot get Native teachings from just anybody, there is a special process involved. Spirituality, teachings and tobacco are sacred.

Some people believe that Sabe sometimes referred to as "Bagwajiwininiwag" (meaning wild or wilderness men) had always been living solely in the Pacific Northwest territory, however, modern biology researchers would indicate otherwise. Perhaps they have expanded their range similar to other animals, e.g. Polar Bears due to climate shift, or a common believe held is that they have always been here. This article highlights the following:

One of my friends, who I trust with my life, has told me they have seen a bi-ped creature northeast of North Bay swim and come out of a lake and walk out on 2 legs...although I have never seen Sabe, I have been face-to-face with several large Mukwa (bear) standing on two legs. Biologists say a $135 \mathrm{lb}$ bear is equivalent to a thousand-pound man in strength so I would imagine an adult Sabe would be of equivalent strength using that formula. I am of the bear-clan and I view Mukwa as a protector and strength. I think if I did see a Sasquatch, I would avoid making eye contact (this advice I have been given by my Elders). (Pitt, J., as quoted in Steer, B., April 2018).

When faced with a predator like a wolf (could easily kill you) out of respect; which I was very close to a large Timber wolf that was following waa'aashkesh (deer), face-to-face early this past fall unarmed in Phelps township (East of North Bay, Ontario, Canada) and it left me alone. 
I have seen a great deal more wolf sign and heard them more often; I do not know about the Ministry of Natural Resources (MNR) biologists but I wouldn't be surprised to learn that the wolves are healthy in number at the time I am writing this. If a wolf can smell a deer up to a couple of kilometers away, no doubt Sabe has similar abilities to avoid detection. Some people who hunt have found track sign only in snow but not in dry conditions; perhaps Sabe stays sheltered during winter like humans do in the shopping malls. Almost any wild big-game animal I have encountered in over 40 years being out in the bush is that they can hear, see \& smell better than us to varying degrees, some moose and deer will wait, motionless and hidden for you to walk past. A Sasquatch would not be any different as shown in this article: "It's my sense that Sabe perhaps chooses to be anti-social and stay away from humans because of how we treat each other and Mother Earth. Maybe one day if we are ready, Sabe may come out of hiding?" (Pitt, J., as quoted in Steer, B., April 2018).

Some Indigenous peoples in the United States refer to Sasquatch as "hairy man" I would imagine in Northern Ontario, Canada it would be difficult to use that terminology accurately to classify Sasquatch over some of the other 2-legged creatures. Decisions have been made to spend far more tax-payers money based on quantitative spins and dirty data than what evidence exists for Bigfoot in our modern world. One only has to see the next big thing in education to see examples. Our contemporary leadership could learn something from Indigenous ways of knowing rather than just exploiting Natives for photo-ops and handshakes.

The Anishinaabe Seven Grandfather teachings, although popularized in many mainstream schools with posters on walls, are mainly just symbolism when used out of context. Think of the Ten Commandments in a Christian or Roman Catholic Separate School or the use of the catechism, if these Anishinaabe teachings are to be used they should be given the same respect.

Each one of the teachings aligns with an animal in a concrete reference, like Mukwa. For "Honesty" it is Sabe or Bigfoot. One would have to think why our ancestors chose the Sasquatch for such an important teaching, the other six align with animals well-known to us today by the western worldview, perhaps Sabe was well-know to the ancestors \& not mythical by today's standards when the Creator created us?

\section{Rocks}

I did some "land-based learning" consulting back awhile ago, interesting that the wee folk come up in these discussions, on Manitoulin Island we call them the Piensak (also known as Paheens) and there's been much talk of them recently in my circles. Nearly every culture in human history has a story about the little people, e.g. fairies in pictographs at Fairy Point, Ontario. The Irish have leprechauns, in Indonesia archaeological evidence suggests hobbit like humanoids found there. Locally on Manitoulin Island they reside on the western high ground in the rocks near Campbell Bay and local oral history suggests that seeing a Piensak or Paheen is bad luck. Pearen (1996, pp. 102-103) and others have written about the wee folk and how they are not visible to everyone. Perhaps only choosing to show themselves to some. I remember reading a long time ago, that D.C. Beard wrote in 1914 that the skeletons on little people were found near Los Angeles and were thousands of years old. One of the stories an Elder told me of the Piensak was that one time they were sitting at the table and a Piensak ran through the room. Stories about the wee folk are varied and can be different from First Nation 
to First Nation. Some Indigenous peoples offer gifts, feasts and ceremony honouring the little people.

\subsection{Pictographs of the Rock Face}

Paddle access Pictographs on the "canvases of stone" are often found on the ancient water highways and migration \& trade routes of Turtle Island (North America) such as the Missinaibi Sites (Kennedy Island Pictograph Site). The pictograph site at Kennedy Island is in close proximity to Dokis First Nation (Dokis Harbour) and also accessible from Lake Nipissing, Ontario. Making meaning of Pictograph Sites. Historically, there has been some work done to summarize pictograph symbols into a code or scripted pictography ideography for interpretation as illustrated in this article:

Pictographs are more than mere ochre paintings or comparable to our modern-day emoji ideograms. Pictographs are sacred to us and my Elders have told me they are deeply connected to ritual. For example, pictographs are often the artist's interpretation of a vision or dream quest that is undertaken for fasting, cleansing or healing. Some Pictographs are also thought to tell a story or narrative and some Indigenous pictographs are thought to represent rituals and offerings. Being connected to culture and spirituality is a sacred experience whether it be from a vision or dream quest and the artist's interpretation as well as selection of site may also be connected to rock types found within the site's stone canvas. (Pitt, J., as quoted in Steer, B., June 2018).

Some Elders and Knowledge Keepers in First Nations communities may be able to lend interpretations to various Pictograph Sites in their traditional territories often through oral histories and Indigenous ways of knowing passed on from the ancestors. The Thunderbird, Bear, Beaver and Canoe images and others at the Kennedy Island Pictograph Site are all well known and some researchers who have argued that some of the morphs may represent the natural elements. It is important to remember that as First Peoples, the Indigenous groups of Turtle Island have lived here for thousands and thousands of years before European Colonialism and some would argue that the inhabitants here did not cross Beringia (the Bering Land Bridge theory) and are pre-Clovis; although despite contemporary research it is still taught as the standard accepted theory in mainstream schools today. History and Social Studies Curriculum methodology still leans too heavily on the doctrine of discovery approach and largely ignores the challenges of Colonialism and Truth and Reconciliation today's learners so desperately need as Treaty partners.

Native Spirituality, healing and cleansing are deeply rooted in a culture in existence tens of thousands of years before Europeans crossed the great water to Turtle Island. Our medicine people were able to exchange ideas in ways that challenge contemporary "hard science" understanding, perhaps this is why some pictographs are so similar in design despite the immense distances between pictographs on the rock faces globally. What is often overlooked in the teaching of history is the advanced Indigenous culture and trading routes in existence on Turtle Island before European Contact. For example, pictographs using ochre procured from the ochre mines of the Mattawa River at Hell's Gate or Devil's Warehouse Island on Lake Superior would have been likely distributed along these advanced trade route systems and used by the artist's of these pictographs. We also know about the connection between 
sacred sites such as Dreamer's Rock near Manitoulin Island and Spirit Rock near Temagami and Pictographs.

\subsection{Preserving the Past of Sacred Landscape Features}

As Indigenous peoples we have a strong Spiritual connection with the land, our Mother Earth. The land is sacred and some sites also hold special spiritual significance. It has been our home for tens of thousands of years before Europeans and the Fur Trade came to Turtle Island. We see connections amongst various specific sacred landscape locations in Ontario within the traditional Indigenous territories. Inside these territories we also see a history of seasonal migration, sacred sites (e.g. spirit rocks, pictographs) as cultural signs and important to our identity as our oral history and ways of knowing have not always been understood and respected from a euro-centric worldview. This article reminds us of the following:

The paddle up pictograph sites tend to be safer from the vandalism of graffiti. Our ancestors had advanced wisdom and visions, knowing to place pictographs under protective rock ledges or in caves for the future. Sometimes we find pictograph sites at different water levels when lakes and rivers ran higher and may have flowed deeper inland than they do today. If you should come across a pictograph site please do not touch them, many have already been lost to time (climatic conditions), and remember these are sacred places. (Pitt, J., as quoted in Steer, B., June 2018).

Many of these sites would have once been considered "prehistoric" by the "Cartier and Kanata narrative' retellings from the old school textbooks that some might nostalgically recall. Often what we already know from our oral history and traditions is later proven by archaeology and methods such as radiocarbon (or carbon-14) dating. Often, we see our governments of the day moving on initiatives such as "integrating" FNMI (First Nations, Metis \& Inuit) content and perspectives into curriculum when integrating (or assimilating) is another Colonial Construct that was not in the spirit of the original Two Row Wampum Belt and the Treaties. Spirituality and culture are deeply connected as this article indicates:

Mt. Cheminis is a spiritual place and we know that sacred sites such as Dreamer's Rock on Manitoulin, neighbouring Spirit Rock and Maple Mountain "Chee-bay-jing" (the place where the spirits go) are spiritual places. Medicine men or Shamans could could communicate at these sites and these locations are known amongst the Indigenous inhabitants of the local First Nations; just as the known Ojibway-Algonquin studies have shown links between communities in the North regions. (Pitt, J., as quoted in Steer, B., March 2019).

We know that our medicine people (sometimes referred to as Healers or Shamans) could communicate at sacred sites (i.e. sacred rock sites) in ways that modern science cannot comprehend; as it is generally understood communicating on another plain of existence that I have often heard referred to as "Spiritual Smartphone". Although we may draw similarities amongst Indigenous communities we must remember and respect the individuality of each First Nation and not view our First Peoples as a homogeneous group. Rituals and ceremony at sacred rocks (or in close proximity to these rocks) would likely have not been identical as we also see range in pictograph sites. For example, medicine wheel teachings and the four directions are not universal on Turtle Island and although some broad generalizations can be 
made, diversity exists as each community or First Nation would be in a different location. Rock and Mother Earth are connected and so to is the cycle of life. History and culture have a strong correlation as this article highlights:

History tells us that Pierre de Troyes in the late 1600's lead an attack on the British at Moose Factory using the Ottawa River North on the voyageur route water highway passing Mt. Cheminis and that since time immemorial the Indigenous peoples of the area (before de Troyes) used the site for rituals. In most cases sacred purposes included ceremonies, fasting and vision questing at these sites. (Pitt, J., as quoted in Steer, B., March 2019).

Our Grandfather Rocks we understand that they have been here longer than us (i.e. The Big Bang Theory) and have seen more and experienced more than our physical bodies can endure; they have what is commonly understood as a memory of the earth's past. There are relationships between these sacred rocks, our rituals, dreams, visions, pictographs and the constellations. Because so much of our knowledge has been lost, my sense is that perhaps our ancestors had a greater understanding of the night sky than we do today. Rocks and formations with features that might resemble an obelisk or have unique tall features may have been used for ceremony (vision/cleansing) or to communicate with the spirit world. The composition or type of the rocks themselves at sites might also have been a factor in site selection and are just a few examples at sites we know of that have been used since time immemorial. This article reminds us of the connection between culture and Spirituality:

Vision questing at rock sites and others was important to finding purpose in life, to understand one's place. This was especially true for males as Native writers such as Basil Johnston have been telling us for a long time, although females could vision quest, their path as givers of life (sacred feminine) was recognized spiritually as well as at a basic level for survival in the harsh conditions in Northern Ontario. (Pitt, J., as quoted in Steer, B., March 2019).

Ceremony at these sites also had a seasonal and cyclical element, such as is true in life. Threats to these sites include climatic conditions, human activity such as pollution, graffiti or natural resource development are just some examples. Undoubtedly as archaeologists such as Thor Conway suggested in the early 1980's, there are more places such as the Sheguiandah Paleo-Indian Quarry Site on Manitoulin Island left to be found again in the dense forests of Ontario as the water levels of the Great Lakes have not always been what they are today throughout time.

Pictographs served many uses, in some cases, an artist's interpretation of a vision, dream or ceremony. In others a narrative or account, still some theorists and knowledge keepers point to pictographs as landscape markers. The Indigenous water highways from the Ottawa River westward through the traditional territories of the Algonquin and Ojibway Peoples had established been trade routes since time immemorial for goods such as ochre used in pictographs. Ochre when combined with fish glue (i.e. Sturgeon oil) or Mukwa (Ojibwe for bear) grease or fat is used by the Anishinaabe for drums and also was used with ochre when ground to a fine powder for painting pictographs which then underwent a chemical process to unite with the rock creating a seal of the ochre with the rock face. Ochre was undoubtedly traded widely as the two known locations (in this area) of ochre on the water highway are Porte de l'Enfer (Hell's Gate) near Pimisi Lake between Lake Talon and Mattawa. The other, an 
island on Lake Superior which has an ancient Ojibway red ochre mine. These mines likely would have provided the ochre for the known pictograph sites in this area, such as, the French River, Temagami/Obabika, Agawa, and near Killarney Park. Most religious or Spirituality beliefs are influenced by the physical environment in which a people live. There is archaeological evidence to support that Indigenous burial grounds in some places used ochre to sprinkle on the grave.

\section{Conclusion}

Pictographs often came from vision and dream ceremonies (e.g. at sacred sites) to represent that vision or dream of the artist from the Creator. After the vision or dream, habitually these ceremonies had a spiritual advisor (e.g. Medicine Man) who would assist the dreamer to interpret their dream before using ochre to create a pictograph. There is also some oral history (e.g. storytelling) to suggest that pictographs were used ceremonially to ensure good hunting, health or when travelling across large bodies of water. Some Elders say that pictographs become one with the rock or grandfather.

Mnidoo Mnising (Manitoulin Island) and the north shore of Lake Huron have impressive high rock vistas such as the La Cloche mountains but more than than just the visual appeal is the interconnectedness of the rocks and sites. For example, local oral Indigenous history tells us that the area is home to Thunderbirds as the sound of thunder is amplified by the quartzite mountains. Closer south towards Manitoulin Island is the bell rock (from which draws the name - La Cloche, "cloche" is French for "bell") that makes the bell sound when struck, used both as a warning bell and later to signal traders perhaps on their way to nearby the Fort La Cloche site (known as the earliest European settlement on the north shore). Mnidoo Mnising is also the location of the Sheguiandah Paleo-Indian rock quarry archaeological site radiocarbon dated to be over 9,500 years old (11,000 calendar years) and the Mindemoya burial cave. The high rocks near Campbell Bay on the island is where the little people or wee folk are said to live in the rocks. Dreamer's Rock just before reaching Mnidoo Mnising on Whitefish River First Nation (WFRFN) land is in close proximity to some pictograph sites, where perhaps an artist experienced a vision or dream which lead them to their pictograph or feasibly from another spiritual site such as in a nearby Pukaskwa Pit near the Killarney Park area. The interconnectedness of spiritual sites, such as Dreamer's Rock near Mnidoo Mnising and those of the Temagami area (Maple Mountain, Spirit Rock, Mount Cheminis, etc..) is that these sacred sites are in the vicinity to pictographs and that association cannot be castoff. Likewise, Medicine Men or Shamans could communicate spiritually at these sacred sites; someone at one location could communicate with another.

Trying to overcome in the current pandemic situation is paramount. The Windigo destructive forces of environment, greed and over indulgence are at work in our contemporary world. Pictographs stand the test of time as signals or warnings. Wendigo (or Windigo) are often represented in Anishinaabe pictograph form as are locations named after Wendigo such as

Wendigo Lake between Larder Lake near Mount Cheminis and Temagami. Indigenous scholar, Robin Wall Kimmerer in her 2013 book entitled "Braiding Sweetgrass" noted that Writer Steve Pitt says that "a Windigo was a human whose selfishness has overpowered their self-control to the point that satisfaction is no longer possible." (Kimmerer, 2013, p. 306). In 


\section{Macrothink}

Ojibway beliefs, Steve Pitt states, "any overindulgent habit is self-destructive, and self-destruction is Windigo." (Kimmerer, 2013, p. 306).

My inaadiziwin (philosophy), my character and way of life with nature or "All My Relations" is interconnected with the land, Aki and my Indigenous Spirituality is interlocked through the topics/themes discussed of Spirit Houses, Sa'be (Sasquatch) and Sacred landscape features such as Spiritual Sites, Ceremony and Pictographs. As with all things and all relations, nothing is a stand alone feature, to look at these themes presented in a non-holistic fashion is a colonized worldview which will not save our Mother Earth.

\section{Acknowledgments}

The narrative research could not have been accomplished without the support of my Ancestors, Elders, family and community members who encouraged and continue to encourage me to speak truth. Miigwech.

\section{References}

https://www.baytoday.ca/columns/the-indigenous-beat/why-i-passed-on-the-liberal-lollapaloo za-707339

Kimmerer, R. W. (2013). Braiding Sweetgrass (1st ed.). Minnesota: Milkweed Editions.

Pearen, S. (1996). Exploring Manitoulin. Toronto: University of Toronto Press.

Pitt, J in Steer, B. (2018, April 26). Sasquatch: Believe It Or Not. Nugget Extra.

Pitt, J in Steer, B. (2018, June 7). Pictographs and City Hall. Nugget Extra.

Pitt, J in Steer, B. (2019, March 9). Lonely Mount Cheminis: A Spiritual Rock. North Bay Nugget.

Pitt, J in Steer, B. (2019, November 7). Spirit Houses A Unique Cultural Tradition. Nugget Extra.

Switzer, M. (2017, August 31). Why I passed on the Liberal Lollapalooza. Baytoday.

\section{Copyrights}

Copyright for this article is retained by the author(s), with first publication rights granted to the journal.

This is an open-access article distributed under the terms and conditions of the Creative Commons Attribution license (http://creativecommons.org/licenses/by/4.0/) 